\title{
MONIKA ŚWIDA
}

Universidade Jaguelônica, Cracóvia

monika.swida@op.p1

\section{A REINTERPRETAÇÃO DO SEBASTIANISMO EM FERNANDO PESSOA}

\begin{abstract}
Monika Świda, A reinterpretação do sebastianismo em Fernando Pessoa [Pessoa's myth of the King Sebastian reinterpreted], Studia Romanica Posnaniensia, Adam Mickiewicz University Press, Poznań, vol. XL/1: 2013, pp. 43-57. ISBN 978-83-232-2542-3. ISSN 0137-2475. eISSN 2084-4158.

The present paper depicts alterations undergone by the sleeping king motif (sebastianism) in the writings of Fernando Pessoa. The data to conduct the study were collected in thematic anthologies and several unpublished pieces. The myth of the King Sebastian was given a congregational dimension by Pessoa, thus conveying his cultural and identity project subsumed under the metaphor of the spiritual empire. Pessoa introduces some readjustments in the way the historical king is to be conceived of. In his theory, Sebastian becomes the figure of the individual effort on the way towards the national renewal. The messianic character of D. Sebastião is defeated in this theory despite having been associated with the figures of either Jesus or the Antichrist. The messiah of the Portuguese foundation myth is replaced with the idea of great man and the task to be carried out in this field, included the metaphor of the Fifth Empire, gains a cultural character. That is why Pessoa's theories must no longer be interpreted in messianic terms. The Pessoa's transformations of the sebastianism analyzed in this article are the starting point for the new national narration in the poetic cycle of Mensagem.
\end{abstract}

Keywords: sebastianism, Pessoa, myth, messianism, the Fifth Empire

\section{SEBASTANISMO vs MESSIANISMO}

Fernando Pessoa opera uma profunda reinterpretação do conjunto dos mitos sebásticos, transformando-os num alicerce da sua ideação do ressurgimento nacional e da construção do império de cultura. As suas ideias acerca dos determinados elementos deste mito nacional encontram-se espalhados por numerosos fragmentos, reunidos nos volumes Sobre Portugal. Introdução ao problema nacional (Pessoa, 1979a), Pessoa Inédito (Pessoa, 1993), Da República (1910-1935) (Pessoa, 1979b), Ultimatum e páginas de sociologia política (Pessoa, 1980), Páginas intimas e de auto-interpretação (Pessoa, 1966) e os inéditos do anexo da tese de doutoramento de Luísa Maria Bernardino de Medeiros de Brito Mendes (Mendes, 2004), não existindo nenhuma acabada obra em prosa que contenha uma reinterpretação pessoana do sebastianismo, embora haja vários planos dela. A reinterpretação pessoana do sebastianismo opera-se em 
vários níveis: desde uma nova visão dos acontecimentos históricos até à reorientação do sentido simbólico da própria figura do malogrado rei. Os textos analisados neste artigo, assim como os que explicam o significado da metáfora do Quinto Império do mito como o império espiritual, império da cultura universal, cumprem um papel preparatório para a reformulação da identidade portuguesa empreendida por Pessoa na Mensagem, uma nova narração nacional (o conceito de Homi Bhabha, 2007) no sentido da reescrita da nação e o ponto de chegada de todo o seu projecto cultural que abrange tanto a sua vida, como a totalidade da obra. A questão fundamental que surge a respeito do sebastianismo pessoano, é a desconstrução e a instrumentalização deste mito fundador pessoano que se opera através da redução dos principais elementos do mito aos recursos retóricos (o que foi por Onésimo Teotónio Almeida evidenciado na sua leitura da Mensagem no quadro do mito soreliano, 1987) e o que faz com que o sebastianismo na versão pessoana perca traços da corrente messiânica.

\section{O MITO SEBÁSTICO}

Ao próprio sebastianismo Pessoa atribuí o papel da religião lusitana ${ }^{1}$ (resultante do facto de ele ser «o único movimento profundamente nacional», Pessoa, 1979a: $191)^{2}$ e popular, de onde vem a sua importância no ressurgimento ${ }^{3}$. O sebastianismo é por Pessoa definido como «um movimento religioso, feito em volta duma figura nacional, no sentido dum mito» (Pessoa, 1979a: 202) ${ }^{4}$ - a conceito do 'mito' reveste-se neste lugar de uma relevância especial: como conclui Teresa Rita Lopes, o sebastianismo pessoano era uma «estratégia» que visava o levantamento do ânimo dos portugueses através da utilização deste «mito congregador» (Lopes, 1993: 352) . O facto

${ }^{1}$ O que não faz com que seja lícito tratar o sebastianismo pessoano como uma crença autêntica, como afirma José Fernando Tavares (2002: 13-14).

${ }^{2}$ Num fragmento inédito Pessoa indica para a existência da continuidade entre a teorização saudosista e a sua no sentido da transformação do sebastianismo: «Educação do sentimento sebastianista: (a) Creação da fé sebastianista (do Bandarra aos nossos dias); (b) Creação do sentimento sebastianista (de Antero de Quental ao saudosismo); (c) Creação - começada agora - da attitude sebastianista», $125^{\mathrm{a}}$ - 99 (apud Mendes, 2004: 328).

3 A motivação sociológica do sebastianismo, e não tanto mítica, foi já antes de Pessoa destacada, como repara Luísa Maria Bernardino de Medeiros de Brito Mendes, por António Sérgio na Interpretação não romântica do Sebastianismo e T. Braga em O Povo português nos seus Costumes, Crenças e Tradições (Mendes, 2004: 107).

${ }^{4}$ Alguns críticos, como Darlene J. Sadlier, reduzem a originalidade do sebastianismo pessoano à combinação do nacionalismo com as correntes vanguardistas (Sadlier, 1998: 27-47).

5 Onésimo Teotónio Almeida escreve a este respeito: «não importa que o mito seja inatingível, já que, no processo dinâmico de se lá chegar, se operam, criam e realizam actos que seriam impossíveis sem esta tensão. Daí a ideia de recuperar o Quinto Império - mito igualmente "nacional" - transformando-o num império espiritual a fim de parecer possível e ser simultaneamente inatingível. Criar um mito anunciando um novo império material não seria acreditável para ninguém, nem Pessoa achava ser isso sequer um bom ideal para o país» (Almeida, 1993: 333). 
de o saudosismo ter sido criado na base do sebastianismo é, na visão de Pessoa, o motivo da sua valorização ${ }^{6}$. De mesma maneira, como passo indispensável para o futuro indica a implantação do sebastianismo pela criação da «atmosfera moral necessária ao saudosismo» (Pessoa, 1979a: 177), o que deve ser obrado através da actividade dos intelectuais que declarariam a guerra ao catolicismo, propondo em troca a figura nacional de D. Sebastião - revela-se neste lugar a ligação com a filosofia da alma portuguesa de Teixeira de Pascoaes ${ }^{7}$. Pessoa indica que no passado o sebastianismo foi sujeito a interpretações erradas, que o concebiam ou como a superstição do povo, ou a fonte da inércia e das fantasias decadentistas (para provar que Pessoa não errou neste lugar basta recordar o anti-sebastianismo do Frei Luís de Sousa de Almeida Garrett). De outra mão, os portugueses que continuam fiéis à ideia do regresso de El-Rei são apresentados como exemplares, como a camada mais valiosa à qual são conferidas as maiores expectativas relacionadas com a actividade futura.

No que diz respeito aos antecessores sebastianistas, Pessoa manifesta grande interesse pelo estudo das Trovas de António Gonçalves Annes Bandarra ${ }^{8}$, dedicando muita atenção às tentativas da decifração destas profecias, apresentando o seu autor como uma figura quase mítica do profeta, o nome colectivo e a voz do povo português, o homem em que vivia «o mistério atlântico da alma portuguesa» (Pessoa, 1979a: 144). Nas páginas dos escritos dedicados ao sapateiro de Trancoso obra-se a sua apoteose - Bandarra é chamado o impulsionador do sentimento imperial, «a voz [...] gritando a existência sagrada de Portugal» (Pessoa, 1979a: 177). Além das profecias de Bandarra, analisa Pessoa também as de Nostradamus e do monge napolitano. Tudo isto não significa que os escritos do maior teorista do sebastianismo, Padre António Vieira, estejam totalmente ausentes nas suas teorias, mesmo que Pessoa estime o jesuíta muito mais como escritor do que teorizador do sebastianismo. Há também neste conjunto de textos pessoanos numerosas reminiscências da leitura dos textos de Teixeira de Pascoaes, o mestre expulso da teoria de Harold Bloom (Bloom, 1997 [1973]).

\section{A FIGURA DE D. SEBASTIÃO}

Uma das reinterpretações fundamentais que Pessoa opera no mito sebástico tem a ver com a natureza e o papel a desempenhar por D. Sebastião. Pessoa multipli-

${ }^{6} \mathrm{O}$ poeta considera estes dois movimentos os únicos verdadeiramente nacionais, $c f .14^{2}-20$ (apud Mendes, 2004: 385).

7 Vale a pena evocar aqui um fragmento intitulado $A$ Religião da Saudade, com a cota 15 B $^{1}$ - 26 (verso): «A religião da saudade é a mais alta forma da fé lusitana, porquanto é a alma da raça, e já não um indício da raça, feito objecto da fé. É messiânica. Os estádios da fé lusitana: (1) estadio catholico (2) estadio sebastianista (3) estadio saudosista» (Teixeira, 1993: 315).

${ }^{8}$ Pessoa elaborou muitos planos da obra dedicada na íntegra ao estudo das Trovas do sapateiro de Trancoso, deixando no espólio alguns fragmentos dela, muitos inéditos, $c f$. o anexo da tese da L.M. Bernardino de Medeiros de Brito Mendes (2004: 303-364). 
ca os regressos do rei, afirmando obstinadamente que há-de haver mais do que um. Também considera possível um equívoco de o destino de Portugal estar, ou não, ligado à figura simbólica do rei (a mesma ambiguidade será visível nas reflexões sobre a probabilidade da construção do Quinto Império). Em conformidade com a tradição sebástica, continua a apresentação de D. Sebastião como a fusão do rei morto em Alcácer-Quibir e do Papa Angélico ${ }^{9}$, ou seja como a união alquímica do elemento material e do espiritual. Noutro fragmento é sublinhado, através dos cognomes tradicionais em correspondência com a visão dos tempos, o seu carácter tridimensional, ou seja: D. Sebastião é ao mesmo tempo o «Rei Nacional», o Desejado (a era presente a Pessoa), o Encoberto (a época por vir) (Pessoa, 1979a: 230). Num excerto inédito, Pessoa explica a tripla natureza da figura de D. Sebastião:

Em el-Rey D. Sebastião 3 cousas: rey de Portugal, o Desejado e o Encoberto.

Como rei de Portugal symboliza a independencia da nação, e como a propria figura e presença d'ella, a sua consciencia de si propria.

Como Desejado, que foi pelo seu nascimento e depois pelo saudoso desejo do seu regresso, elle representa a Esperança, a Confiança e a Força.

Como Encoberto, que se tornou $\square$, elle representa o Imperio.

Tanto assim é que, com a ida d'elle, as 3 cousas, que a sua Pessoa representa, se perderam: a independencia, porque dois annos depois nas $\square$ a Hispanha; a esperança e a força porque com elle levou perdemos a sciencia de governar e de confiar em nós; o Imperio, porque na morte do rei, e na obra Imperial que se the seguiu, pouco a pouco se foi sumindo o nosso logar imperial entre as nações (Mendes, 2004: 315) ${ }^{10}$.

É também estabelecida a identidade entre El-Rei e Osíris - talvez baseada não só na semelhança da situação anormal do corpo de ambos os defuntos, mas também na profecia do futuro reinado de D. Sebastião vinculada ao deus da vida no além. Conforme a visão profética do mundo, Pessoa acredita na duplicidade dos significados, procurando tanto nos acontecimentos, como nos entes (tais como uma nação) o face oculta para os humanos contemporâneos e só visível para os iniciados (em alguns casos). De acordo com esta lógica afirma o poeta o facto de a primeira vinda de ElRei ter tido lugar em 1640, mas não na figura do rei D. João IV (como anunciou na altura Padre Vieira), mas no «facto abstracto de Independência» (Pessoa, 1979a: 183) (isso não estranha dado que na doutrina profética de Pessoa o acontecimento é igual ao homem). Também como a exemplificação dum destes acontecimentos a que, ainda que anunciados nas Trovas de Bandarra, não se prestou atenção, dá Pessoa expressão da sua convicção de ele próprio ser a encarnação do Desejado: «ora neste último ano (1888) deu-se em Portugal o acontecimento mais importante da sua vida nacional

${ }^{9} \mathrm{Da}$ acordo com as teorias do Padre Vieira, talvez influenciado por Savonarola.

10 A continuação desta ideia encontra-se noutro fragmento inédito $(125-93)$ : «com D. Sebastião, figura symbolica, desappareceram: (1) a independencia de Portugal, (2) a sua Grandeza, (3) o seu Imperio - grandeza e imperio são cousas distinctas porque se é certo que só pode haver imperio, isto é, dominio sobre os outros - em grandeza, pode contudo haver grandeza sem imperio, brilho sem substancia, força sem influencia» (apud Mendes, 2004: 327). 
desde as descobertas; contudo, pela própria natureza do acontecimento, ele passou e tinha de passar inteiramente despercebido» (Pessoa, 1979: 174) ${ }^{11}$.

Noutro fragmento testemunha já de modo aberto o facto de em 1888 se ter dado a segunda vinda de D. Sebastião, ainda que continue encoberta. Pessoa propõe também três datas do reaparecimento do Encoberto: 1640, 1888 e 2198, mas o que lá interessa mais é a introdução do conceito dos falsos Encobertos (se calhar emprestado do messianismo judaico), chamados «as figurações falsas do Encoberto Real» (Pessoa, 1979a: 207) e que aparecem na proximidade temporal das encarnações verdadeiras do verdadeiro Desejado. Como tais indica Pessoa D. João IV, Marquês de Pombal e Sidónio Pais, afirmando que «qualquer dos três realizou em si sinais distintivos do Encoberto» (Pessoa, 1979a: 207), mas o que os distingue da figura messiânica real é a transitoriedade da obra civilizacional ou política deles. Num dos excertos desliga o sebastianismo da personagem do soberano morto em África, afirmando equivaler a figura de El-Rei ao número cabalístico de Portugal. Neste mesmo escrito, o regresso de D. Sebastião, signifique este o que significar, é idêntico à antemanhã do Quinto Império e a revitalização da «Alma da Pátria», ao restabelecimento da unidade ibérica e à vitória sobre o catolicismo. A par disso, Pessoa conclui que o tempo propício para a animação do «sentimento sebastianista» (Pessoa, 1979a: 194) ainda não chegou, ainda que no texto seguinte designe a data do Grande Regresso para o ano de 1924.

Quanto à natureza do regresso de $\mathrm{D}$. Sebastião, a inovação de Pessoa consiste na introdução da metáfora da metempsicose no imperativo de activação dos membros da nação - deste modo a incarnação do Encoberto torna-se a obra simbólica do esforço individual:

Assim, morto D. Sebastião, o corpo, se conseguirmos evocar qualquer cousa em nós que se assemelha à forma do esforço de D. Sebastião, ipso facto o teremos evocado e a alma dele entrará para a forma que evocámos. Por isso quando houverdes criado uma cousa cuja forma seja idêntica à do pensamento de D. Sebastião, D. Sebastião terá regressado, mas não só regressado modo dizendo, mas na sua realidade e presença concreta, posto que não fisicamente pessoal. (Pessoa, 1979: 196) ${ }^{12}$

É a comunidade entre o real, concreto e o imaterial, que faz com que o acto do regresso de D. Sebastião seja transferido para a esfera puramente espiritual (o que entra em alguma contradição com certos escritos sobre a natureza do imperador do Quinto Império). Além disso, no final do texto analisado Pessoa fala do regresso real e não simbólico de $\mathrm{D}$. Sebastião (equivalente ao retorno da pátria à grandeza perdida). Noutro excerto, que estabelece a identidade entre a figura de El-Rei e Portugal, fala-

${ }^{11} C f$. também o texto de José Edil de Lima Alves (1993: 257).

12 Sobre o sebastianismo trans-histórico que se renova nas almas individuais escreve D. Pereira da Costa (1971: 185). Brunello de Cusatis interpreta a ideia do regresso de D. Sebastião literalmente como a metempsicose, com o que não podemos concordar na luz dos textos pessoanos, visto que a evocação desta ideia parece-nos além de tudo metafórica (2005: 19). Cf. também: Mendes (2004: 144) e Siewierski (1998: 40). 
se de novo do regresso concebido simbolicamente ${ }^{13}$, repetindo esta ideia num inédito consagrado à interpretação das profecias de Bandarra, Pessoa repete esta ideia: «não só a el-rey $D$. Sebastião, não á sua ida, isto é, a seu desapparecimento (ou morte) e esta ida e aquella vinda, similhantemente, teem de ser interpretadas como a ida e a vinda, não da pessoa carnal do Rey, senão da substancia que essa pessoa e o seu nome symbolizam» (Mendes, 2004: 314).

Daí vem o problema do sebastianismo tradicional que, mesmo que essencialmente não errado, foi enfraquecido pela espera da salvação externa enquanto, como já se provou, a figura simbólica de El-Rei deve ser erguida dentro de cada homem e só depois projectada «para o mundo chamado externo» (Pessoa, 1993: 228). Aos sebastianistas de outrora, crentes no regresso pessoal e carnal de D. Sebastião, Pessoa chama «litteraes» (Pessoa, 1993: 229) 14. Em contrapeso, o teorizador indica explicitamente qual o dever dum indivíduo na obra do regresso de D. Sebastião: «deve cada um de nós fazer por em si realizar o máximo que pode de similhante ao Desejado. A somma, a confluencia, a synthese por assim dizer carnal d'essas ansias será a pessoa do Encoberto» (Pessoa, 1993: 228) - é patente, também neste fragmento, a tensão dialéctica entre o carácter carnal e simbólico de El-Rei. Nesta perspectiva, as afirmações irónicas sobre os portugueses que se consideram auto-D. Sebastiãos revelam-se mais sérias do que podia parecer à primeira vista. Mesmo que entre as reflexões formadas em torno da figura de D. Sebastião quase não haja perplexidade quanto à abolição da sua tradicional natureza messiânica, uma vez que El-Rei é apresentado como uma figura simbólica do renascimento pátrio, no mesmo texto Pessoa esclarece dúvidas em relação a esta questão, negando a existência do messias de género dum indivíduo: «não há homens salvadores. Não há Messias» (Pessoa, 1993: 228), destacando a figura dum homem dotado que tenha a função de um estimulador de almas, um despertador de energias alheias, transferindo a responsabilidade pela salvação nacional para a própria nação: «Salvar um homem a um povo inteiro - como o poderá fazer, se esse povo inteiro não fizer por salvar-se - isto é, se esse povo inteiro não quizer ser salvo? "Obra tu a tua salvação" diz S. Paulo; e o grande homem é aquelle que mais profundamente compellir cada alma a, de facto, operar a sua própria salvação» (Pessoa, 1993: 228). Neste sentido o facto de o próprio Pessoa assumir o cargo duma incarnação de El-Rei não estranha e parece ainda bastante justificado, tomando em consideração os planos de livros e projectos educativos que lhe ficaram por escrever. Portanto, fica claro qual é o sentido reinterpretado do regresso de D. Sebastião, assim como a mudança da perspectiva consistente na transferência da responsabilidade dum indivíduo carregado do destino mes-

${ }^{13}$ Sobre o mito como a essência do sebastianismo fala também Henryk Siewierski, escrevendo: «O encoberto volta cada vez que se vive o seu sonho e transforma o sonhador em co-criador das grandes obras que Deus previu» (Siewierski, 1982: 8).

${ }^{14}$ Como sublinha Mendes, Pessoa distanciou-se dos que percebiam a figura de El-Rei «como o próprio significado e não como simples manifestação deste» (Mendes, 2004: 51). 
siânico para a comunidade nacional ${ }^{15}$. O papel tradicional da memória dum grande passado material ${ }^{16}$ e da tentativa da recuperação das condições do império colonial é agora desempenhado pelo desejo da efectivação do sonho nacional no interior dos membros da comunidade patriótica. O que é também característico, é a abolição do elemento de sacrifício ${ }^{17}$, indispensável em todas as teorias messiânicas, bem presente não só no mito sebástico, mas também nas ideias de Teixeira de Pascoaes - em Pessoa, este transtorno pode estar relacionado com a contestação do humanitarismo de cada espécie e com o culto da força ${ }^{18}$, bem expresso no Ultimatum, Apontamentos para uma estética não-aristotélica ou $O$ Interregno. Todavia, a condição do sacrifício reaparece como indispensável em vários lugares da Mensagem.

D. Sebastião é no contexto do Quinto Império visto como o seu «emissário» (Pessoa, 1993: 228). O Quinto Império equivale ao seu regresso simbólico: «então se dará na alma da Nação o fenómeno imprevisível de onde nascerão as Novas Descobertas, a Criação do Mundo Novo, o Quinto Império. Terá regressado El-Rei D. Sebastião» (Pessoa, 1979a: 255). O Quinto Império inaugurar-se-á, pois, através da incarnação do sonho sebastianista ${ }^{19}$ em cada português; Eduardo Lourenço com justeza enquadra a reflexão sobre as teorias pessoanas num processo duradouro da autoexaminação e formação duma imagem nacional através dos mitos, concluindo:

15 Este conceito da interiorização do destino regenerador também é comum a Pessoa e Pascoaes, baseando-se na realização em si, por cada indivíduo que compõe a comunidade nacional, desta transgressão.

${ }^{16}$ O papel da memória colectiva é bem visível no poema Viriato da Mensagem.

17 Mesmo que alguns estudiosos pareçam não ter dado conta desta mudança de perspectiva, como por exemplo Dalila Pereira da Costa, que no artigo «A mensagem messiânica» põe observações que devem ser contestadas: «no sebastianismo, como religião portuguesa clamada por Pessoa, o Sacrifício será assim noção central» (Costa, 1993: 272) - nada está menos em conformidade com as ideias pessoanas, anti-humanitaristas e anticristãs no sentido da valorização do sacrifício, do que esta afirmação.

18 Como nota Brunello de Cusatis, o antihumanitarismo pessoano era tão forte que o levou à renúncia das doutrinas teosóficas, (2005: 23 e seg.).

${ }^{19}$ Um dos conceitos herdados por Pessoa do espólio pascoaesiano é com certeza o de sonho, sendo este em Teixeira a metáfora da actividade criadora do homem (contraposta à passividade simbolizada pelo sono, de modo que a condição da existência humana seja concebida como o eterno cambaleio entre o sono e o sonho, (Coutinho, 1995: 130). No entanto, o sonho e o sono são, ao lado de outros pares antinómicos que constróem o sistema filosófico pascoaesiano (tais como existir : ser/viver, realidade : verdade, ausência : presença, aparência : aparição), uns dos conceitos básicos. O sonho é em Teixeira de Pascoaes não só o sinónimo da actividade espiritual humana (como é também em Pessoa: «Deus quer, o homem sonha, a obra nasce» (Pessoa, 1993: 47), mas também uma das metáforas que descrevem o modo de ser de Deus na sua ontologia (Coutinho, 1993: 301). Esta metáfora de sonho para a designação da realização das profecias sebastianistas não está presente só em Pessoa ou Pascoaes, mas também é empregue por Afonso Lopes Vieira, (Pires, 1982: 100). O sonho é uma forma de acesso à realidade também na poesia de Pessoa, aliás, no fundo, romântica (Moisés, 1979: 62 e seg.) Na Mensagem o sentido simbólico do sonho relaciona-se com a condição do visionário: «O sonho é ver as formas invisíveis» (Pessoa, 1993: 48). 
singular inversão e singular constância de um mito: de objecto de mitificação colectiva, D. Sebastião volve-se objecto de apropriação colectiva, ao mesmo tempo, de absoluta «impessoalidade». O Portugal-D. Sebastião de Pessoa é todo-o-mundo-e-ninguém, como ele, Pessoa-D Sebastião, é ninguém-e-todo-o-mundo [...] Esse D.Sebastião-Pessoa não anuncia mais que um império cultural sem imperialismo de culturas nem de verdades, mero espaço da absoluta liberdade de cultuar as múltiplas e inconciliáveis «verdades», que, na ausência definitiva de Deus, nos servem de simulacros plausíveis e implausíveis de verdadeiro. Assim, o que começou como um sonho de um império reditivo termina com Pessoa em império de sonho (Lourenço, 2001: 141-142),

o que, aliás, se parece com a visão do Quinto Império de António Vieira, obviamente passando por cima das diferenças resultantes das épocas e da situação perante o cristianismo, para não falar já do catolicismo ${ }^{20}$. Esta longa citação resume de maneira mais certa e adequada as transformações que operou Fernando Pessoa nos mitos nacionais do sebastianismo e Quinto Império. O que é preciso sublinhar é o facto de o sebastianismo pessoano ser universalista e de modo nenhum nacionalista, sendo a ultrapassagem da estreiteza da circunstância nacional a condição indispensável para a realização dum sonho ${ }^{21}$ imperial - como constata Seabra: «Portugal-Império caracteriza-se, espiritualmente, por uma pluralidade potencialmente infinita» (Seabra, s.d.: 92).

\section{D. SEBASTIÃO - JESUS - ANTICRISTO}

Os elementos cristãos no sebastianismo pessoano também não se opõem à tradição deste movimento religioso - Jacinto do Prado Coelho chama ao pensamento pessoano que está na base da elaboração da Mensagem e de outros fragmentos de índole patriótica, de maneira eufémica, «vagamente cristão» (Coelho, 1983: 32). É absolutamente indiscutível a atitude pessoana quanto ao catolicismo romano, sendo a sua posição absolutamente negativa e compatível com a dos seus antecessores, como por exemplo Antero de Quental. É certo que a Igreja Católica é pelo poeta considerada um inimigo cuja extinção na terra portuguesa é uma condição indispensável para um renascimento pátrio, dado que a Igreja é um factor de degeneração. A luta contra a igreja católica e a sua substituição pelo mito nacional do sebastianismo são as circunstâncias necessárias do renascimento da nação (de acordo com esta lógica, Pessoa considera úteis todos os sistemas religiosos sob a condição de serem nacionais, populares e susceptíveis de evolução e de adaptação).

${ }^{20}$ Maria Leonor Carvalhão Buescu escreve a propósito desta visão: «é necessária a realização da fórmula que obsidia o pensamento milenarista <unum ovile unum pastor $>$ : a conversão universal e a redução de todas as religiões, heresias e seitas a uma só religião», (Buescu, 1992: 14).

${ }^{21}$ Sobre o conceito de sonho em Jung, distinguindo a profecia de função prospectiva do sonho, escreve A. Quadros (2001: 376). 
Já a definição da sua disposição em relação à religião cristã é menos unívoca, dependendo do fragmento que se analisa, visto que o poeta apresenta opiniões extremas: da assunção do carácter cristão do futuro império à proclamação deste como o reinado do Anticristo (analisado em diante) ${ }^{22}$. O conceito de cristianismo, tanto pelas suas conotações religiosas, como históricas (o terceiro império na ordem intelectual/ espiritual), serve a Pessoa também de ponto de partida para a ideia do universalis$\mathrm{mo}^{23}$ - como a fundação da verdadeira Igreja Católica (cristã) sob o nome da Nova Jerusalém é também designado o Quinto Império; num dos fragmentos destaca Pessoa o carácter sincrético da tradição do cristianismo ${ }^{24}$ que é um factor que tornaria mais plausível o carácter cristão do império visionado. Como afirma, a nossa civilização é fundamentalmente cristã, o que possibilita a previsão da evolução das sociedades moldadas segundo os princípios do cristianismo. Contudo, o cristianismo é também definido, sobretudo na época da elaboração das teorias do sensacionismo e do neopaganismo ${ }^{25}$, como «um produto da decadência romana» (Pessoa, 1966: 225), responsável pelo «stado [sic] perpètuamente mórbido da nossa civilização» (Pessoa, 1966: 225). Segundo o poeta, este sistema religioso assenta sobre a base da cultura grega e da administração romana, de modo que o cristianismo possa ser considerado um paganismo decadente. A religião cristã é então responsabilizada pela doença da civilização europeia, sendo a morte da Igreja Católica e a vinda do Anticristo a condição inescusável para a paz na Europa.

A figura de Jesus aparece nos escritos pessoanos sempre no sentido ocultista e sem referência ao seu vulto paradigmático do redentor (tão frequentemente utilizado pelos autores das teorias de género messiânico). Assim Jesus é apresentado como um iniciado divino (a esta categoria pertence também Shakespeare) e como um adepto superior - o seu cunho mais relevante não é a morte salvadora, mas a dupla natureza

${ }^{22}$ Cf. também (Serrão, 1981: 167-168).

23 E. Frias identifica este universalismo ao catolicismo - «o mais absoluto espírito da universalidade» (Frias, 1971: 82). Mais ainda, para ele este catolicismo é de modo incompreensível a condição para o ressurgimento nacional: «só a consciência da catolicidade, em plena e viva significação religiosa, pode alcançar, com a re-ligação às tradições nacionais, esse despertar fecundo» (Frias, 1971: 83). Esperamos que o significado desta catolicidade seja sempre o universal, vieiriano - mesmo assim, tendo em conta a opinião unívoca de Pessoa sobre o catolicismo, esta metáfora não parece ser muito feliz.

${ }^{24}$ Ainda que Pessoa outro lugar admita também a possibilidade do aparecimento dum novo sistema religioso, mas só após a realização do Quinto Império, «fora dos nossos <tempos>», 125 A - 34/36 [dact] [Bandarra] (Pessoa, 1979a: 150).

${ }^{25}$ Outra questão é levantada pelo projecto do neopaganismo português desmentindo a tentativa pascoaesiana e junqueiriana da junção do cristianismo e paganismo, Pessoa aclama o abandono do cristianismo seguido de «uma reconstrução transcendental do espírito pagão», 55 I - 33 [dact] [Atlantismo], (Pessoa, 1979a: 226) e da criação do «Paganismo Superior, o Politeísmo Supremo» («O que calcula que seja o futuro da raça portuguesa?», Pessoa, 1979a: 246) - desta maneira Pessoa revela-se um adepto do politeísmo, ainda por cima hereticamente assumindo a identidade de todos os deuses, cf. $125 \mathrm{~A}-33$ [dact] [Bandarra] (Pessoa, 1979a: 146). 
humana e divina, e relacionada com isso existência em duas pessoas distintas. Em alguns fragmentos também a figura do imperador do Quinto Império é identificada com Cristo-adepto, sendo o Quinto Império igual à Segunda Vinda de Jesus. De outro lado, numa carta ao director do Jornal do Comércio, Pessoa designa El-Rei com o nome pela tradição reservado para Jesus Cristo, isto é o Nosso Senhor, o que é sem dúvida um acto herético, visto que Jesus é neste caso reduzido à transposição do sentido messiânico no D. Sebastião.

$\mathrm{O}$ que se afigura bastante contraditório com as ideias anteriores é a ligação da personagem do imperador (supostamente El-Rei) com a figura de Ante- ou Anticristo (a distinção entre o Ante- e Anti-cristo é conforme o significado etimológico dos prefixos: ora temos a ver com quem vem «antes de», ora com quem está «contra», ambas as designações aparecem nos escritos pessoanos), levando à afirmação de que o terceiro imperador (o do ano 2198) será Antecristo no sentido de desempenhar um papel do arauto de Cristo. De outra mão, com certeza afirma Pessoa que Anticristo, representando a força espiritual e a Inteligência ${ }^{26}$, terá como o país de origem Portugal, predestinado para esse fim pelo facto de ter levado a cabo a aventura das Descobertas, a obra por si mais representativa da energia intelectual. A vinda de Anticristo é igual ao regresso de D. Sebastião, ampliado o significado deste do mero renascimento da nação para a criação do Quinto Império, ainda que compreendido neste contexto de maneira completamente heterodoxa $\mathrm{a}^{27}$ - a figura de Anticristo é um elemento que leva à discussão fundamental no que diz respeito ao carácter não só de D. Sebastião, mas também do Quinto Império da lenda. Pessoa não toma também uma posição unívoca em relação ao carácter do Anticristo: num destes trechos sublinha a convicção do carácter real deste imperador figurado, e não, como dantes, a ideia da atmosfera, ambiente, ao passo que noutro destaca a natureza puramente espiritual da vinda do Anticristo que havia-de se obrar através do combate das ideias no tempo. Pessoa deixou também uma visão catastrófica do Quinto Império, na qual esboça o desaparecimento do mundo, que só Portugal-civilizador poderia sobreviver. A missão de Portugal é explicitamente chamada divina (o que equivale à anti-cristã):

mas a grande obra anti-cristã (anti-cristã em tudo, anti-democrática, anti-católica, anti-monárquica) deve ser feita. Tristes de nós se faltaremos à missão divina que Aquele nos pôs ao Ocidente da Europa, e tais nos fez quais somos, nos impôs quando nos deu este nosso acesso e transcendido espírito aventureiro. Depois da conquista dos mares deve vir a conquista das almas. O resto - a felicidade nacional, a boa administração, a liberdade, a lealdade, a honra - não são senão o lixo que atulha o caminho dos nossos gestos! Sursum corda! (Pessoa, 1980: 240$)^{28}$.

${ }^{26}$ Embora num inédito represente a inteligência material, o sinónimo do domínio da força, $c f$. $125^{\mathrm{a}}-15^{\mathrm{v}}$ a 18 (apud Mendes, 2004: 353), e noutro ainda o das forças anti-espirituais, inclusive a igreja católica, $c f .55 \mathrm{~B}-72$ a 78v (apud Mendes, 2004: 404).

${ }^{27}$ Como afirma Joel Serrão, o papel único de Anticristo nesta visão é o de abrir o caminho ao supra-Camões, que é o verdadeiro anunciador do Quinto Império (1981: 185).

${ }^{28} C f$. também o excerto inédito que parece uma das versões deste fragmento: $14^{5}-100$ (apud Mendes, 2004: 406). 
Também noutro fragmento o império por criar implica ou ainda exige a abolição dos princípios cristãos: do humanitarismo e da democracia em prol da força, violência e crueldade, segundo o exemplo da Alemanha:

Os que querem um Portugal honesto, feliz, rico e honrado, querem a negação da acção civilizacional portuguesa, querem que desçamos ao burguesismo nacional duma pseudo-nação como a Suíça ou a Bélgica, querem que abandonemos o nosso grande papel na construção do novo mundo, que abdiquemos de realizar em espírito aquilo que realizámos outrora em corpo - para o alargamento do mundo e a descoberta de novas terras, novos mares, novos céus. Mais alta é a missão portuguesa do que tudo quanto pode sugerir a barriga dos portugueses [...] Mais alta é a obra e ela a ser feita, terá de ser feita quebrando aos pés toda a longa podridão humanitária, democrática, organizando uma aristocracia forte, dominando completamente a nossa plebe ineficaz salvo escravizada (Pessoa, 1980: 239) ${ }^{29}$.

Outra questão é a colocação temporal do pronunciado reino do Anticristo - num dos fragmentos o reinado do Anticristo é visionado como anterior ao Quinto Império, compreendido como o da segunda vinda de $\mathrm{Cristo}^{30}$, enquanto noutro é posterior ao império espiritual e identificado com a «dissolução da nossa civilização» (Pessoa, 1979a: 185). No contexto destas reflexões surge também a noção vieiriana do Império do Espírito Santo, seguido por o de Anticristo, mas também sem continuação noutros fragmentos.

A ideia da identificação de D. Sebastião com Anti-(Ante-)cristo só aparece em alguns fragmentos pessoanos, desprovidos tanto da indicação da atrbuicao a qualquer texto/projecto, como da data. Se bem que o conceito de Anticristo entre em relação com as ideias do Super-Homem de Álvaro de Campos, com um nítido cunho nietzschiano, esta visão não se encontra desenvolvida nem mencionada noutros fragmentos pessoanos e de modo nenhum na Mensagem, o que faz com que a tratemos como uma das versões avulsas, que é preciso indicar, mas que não entram no grupo das ideias que formam uma interpretação global. A ideia de Anticristo e a identificação do seu reino com o Quinto Império é por nós tratada como o outro sinal do nietzchianismo pessoano (e como tal correspondente às anunciações antropológicas e estéticas de Álvaro de Campos), assim como, ou ainda sobretudo, do seu fascínio pelo ocultismo.

No material examinado neste artigo não faltam contradições, ou mais justo seria dizer que elas fazem parte inextricável deste, e não só, conjunto de textos pessoanos. A primeira explicação deste estado de coisas são a fragmentariedade dos textos estudados e a falta da sua organização, que ao lado dos problemas com a datação e com a evolução evidente não só dos interesses pessoanos, mas também das suas ideias, faz com que o nosso corpus se apresente como um labirinto com vários becos sem saída. Também este labirinto, visto que vários fragmentos do espólio ainda continuam sem

${ }^{29}$ A propósito destas divagações veja a identificação de supra-Camões e Super-Homem de Álvaro de Campos com as ideias de Nietzsche escreve Serrão (1981: 145). Cf. também (Azevedo, 2005: 120). António Costa Pinto sublinha o facto de Pessoa ser um dos raros exemplos dos entusiastas do neopaganismo antihumanitarista da origem germânica na Península Ibérica (1996: 355).

${ }^{30}$ Cf. também (Serrão, 1981: 167-169). 
publicação, não é estável e pode um dia, após a edição da totalidade dos textos pessoanos, transformar-se noutro labirinto, ainda mias complexo.

Há também outra explicação das contradições na obra pessoana, nomeadamente a consciência da heteronímia original, muito mais profunda, que ultrapassa o jogo das «ficções de interlúdio» e que já se manifestou no Livro do Desassossego e que faz com que Eduardo Lourenço denomine este texto como o texto suicida (Lourenço, 1993: 87 e seg.). É obvio que não se pode estabelecer o paralelismo imediato entre a situação textual dos escritos dedicados à ideias sebásticas e os fragmentos que constituem o Livro do Desassossego, sobretudo por motivo das diferenças genéricas, mas mesmo assim achamos a proposta de Eduardo Lourenço interessante também a nível do projecto existencial que afinal abrange toda a vida e obra pessoana.

\section{A IDEIA DE GRANDE HOMEM}

Em Pessoa, a figura do messias é substituída por a do grande homem, próximo ou, por vezes, igual à noção do génio. A temática de génio surge frequentemente nos escritos pessoanos acerca da problemática nacional. Embora o conceito de messias pessoal já tenha sido abandonado por Pessoa, o homem de génio é concebido como redentor simbólico da pátria ${ }^{31}$, só que no sentido de estimulador das almas, de homem providencial. O grande homem caracteriza-se pela «personalidade espiritual» que vem das feridas operadas pelas crises espirituais - esta condição do sofrimento, o preço da grandeza, faz parte não só do conjunto das características que atribui Pessoa às personagens inusitadas, mas está bem presente na tradição dos heróis, sobretudo do tempo do Romantismo.

Ao homem de génio é também atribuída uma função destacada na obra da reforma social, isto é um papel da origem e do dirigente das mudanças que em suma constituem a civilização (Pessoa, 1979b: 301). O homem de génio é nas teorias pessoanas o porta-voz da nação, o meio através do qual a nação se exprime, dado que é «a concentração individual das forças íntimas da Nação» (Pessoa, 1979b: 366). Num fragmento inédito, o génio é chamado «um prenuncio da humanidade futura» (Mendes, 2004: 302 $)^{32}$, sendo sublinhado o seu carácter sintético, da união de duas inteligências (a tríade é já a característica da divindade neste contexto). Faz parte deste assunto o interesse que Pessoa prestou ao conceito da iniciação, dividindo os iniciados em três categorias, ou seja: os que passaram pela iniciação exotérica, esotérica e divina - no grupo dos homens de génio relevante é este último caso. A iniciação divina é um dom da força superior que pode também ser chamada Deus - «o tipo supremo» desta iniciação é Jesus. O iniciado divino equivale na teoria de Pessoa ao génio, e assim sendo, o outro exemplo evocado é Shakespeare.

\footnotetext{
${ }^{31}$ Sobre o conceito místico da pátria escreve Frias (1971: 86).

${ }^{32} C f$. também o excerto $125^{\mathrm{a}}-4^{\mathrm{v}}$ (Pessoa, 1979b: 299).
} 
O homem de génio é também uma exemplificação típica do mecanismo do reconhecimento tardio do significado dum acontecimento ou personagem que não revela de vez as suas qualidades superiores - como o caso exemplar deste desconhecimento evocava o poeta a si próprio. O poeta indica também alguns outros grandes homens, como que tirados dos textos românticos: Alexandre Macedónio e Napoleão. A existência dos génios em Portugal é também um argumento a favor da superioridade cultural de Portugal sobre a Inglaterra, dado que lá os génios são cada vez mais «mesquinhos», enquanto Portugal, segundo Pessoa, é o único país «em que o tipo superior de mentalidade teve progresso [...] do princípio do século dezanove para cá» (Pessoa, 1979a: 223). O aparecimento dos génios literários faz parte das condições imediatas para a criação do império de cultura. O que é imprescindível destacar é o facto que logo no princípio da teorização pessoana do Quinto Império, iniciada nas páginas da Nova Poesia Portuguesa, surgiu o papel a desempenhar nesta obra pela literatura, sendo o génio esperado designado com um nome do poeta.

O lugar que na teorização pessoana ocupam os grandes homens, pelos investigadores comentado como derivado da inspiração na leitura de Carlyle, pode também provir de Teixeira de Pascoaes e, indirectamente, por este intermédio, da tradição romântica francesa. Para Pessoa, o grande homem é o representante da nação e ao mesmo tempo emissário das forças maiores, tal como por exemplo Sidónio Pais, Presidente-Rei, o falso encoberto. Os grandes homens são, tanto para Pessoa, como para Pascoaes, as fontes do espírito nacional. No artigo «Camões, Pascoaes, Pessoa - ou o mito poético da Nova Renascença» (Seabra, 1980) José Augusto Seabra fala duma tríade fascinante, composta pelos poetas acima mencionados, quer dizer: Pascoaes e Pessoa centrados em volta do mito camoniano. Segundo Seabra, Pascoaes apresenta o momento culminante da deificação da figura do poeta renascentista, enquanto Pessoa é já o indício da necessidade da metamorfose num novo mito, isto é, supra-Camões, que multiplicado em poetas heteronímicos, «anuncia ao mesmo tempo a pluralização da pátria - quer dizer, da língua que para Pessoa ela acima de tudo é» (Seabra, 1980: 25).

É no entanto evidente que não é lícito falar do sebastianismo em Fernando Pessoa no sentido em que se fala do sebastianismo de António Vieira, mas antes da utilização instrumental, da função retórica (ou soreliana) do mito sebástico. Não se pode discorrer também sobre o messianismo pessoano, visto que embora ainda seja possível considerar messianismo o conjunto de ideias nas quais se opera a abolição do conceito dum messias pessoal, já não é assim no caso da abolição da própria ideia da redenção, operada por Pessoa e substituída pelo projecto da reformulação da identidade nacional, levado a cabo na Mensagem. Alguns investigadores, tais como Dalila Pereira da Costa, dispensaram atenção a esta questão, reparando na confusão terminológica e chegando à conclusão de que não se deve falar do messianismo pessoano, antes do missionismo com elementos da visão messiânica (Costa, 1988: 272); nós julgamos que é mais apropriada a denominação do nacionalismo místico. Na nossa opinião só 
é legítimo falar no sebastianismo pessoano no sentido das transformações do mito sebastianista, conquanto, sempre com a consciência clara de que a função e o remate destas transmutações é já de índole distinta, cumprindo o mito sebastianista apenas o papel do mito congregador.

Como pudemos observar, a teorização pessoana centrada em volta do mito sebastianista, no sentido do mito congregador, «religião lusitana», abrange várias ideias, retomadas mais tarde na Mensagem: desde a transposição da função de D. Sebastião para a obra individual dos portugueses, passando pelos escritos dedicados ao cristianismo, Anticristo e o eventual carácter religioso do Quinto Império, até às divagações consagrados ao papel dos grandes homens na futura obra. As incoerências e contradições são as características constantes do conjunto dos textos consagrados a esta temática, tanto mais patentes, quanto mais relevante a ideia analisada. Como também já foi mencionado no início deste artigo, as reflexões pessoanas acerca do sebastianismo e Quinto Império só preparam a nova escrita da nação que na nossa opinião é a Mensagem, onde as ideias desenvolvidas nestas páginas encontram a sua expressão mais acabada e coerente, constituindo um novo projecto identitário português.

\section{BIBLIOGRAFIA}

AlmeIDA, Onésimo Teotónio (1987): «Mensagem» - uma tentativa de reinterpretação. Angra do Heroísmo: Direcção Regional dos Assuntos Culturais.

Almeida, Onésimo Teotónio (1993): «A ideologia da Mensagem». In: F. Pessoa, Mensagem. Poemas esotéricos. Edição crítica, ed. J.A. Seabra. Madrid 1993: Coleção Archivos. Fundação eng. A. Almeida, 329-336.

Alves, José Edil de Lima (1993): «A moderna épica portuguesa em Mensagem». In: F. Pessoa, Mensagem. Poemas esotéricos. Edição crítica, ed. J.A. Seabra. Madrid: Coleção Archivos. Fundação eng. A. Almeida, 246-257.

Azevedo, António (2005): Pessoa e Nietzsche. Subsídios para uma leitura intertextual de Pessoa e Nietzsche. Lisboa: Instituto Piaget.

Bнавна, Homi K. (2007): «Introduction: Narrating the nation». In: Nation and Narration, ed. H.K. Bhabha. London: Routledge.

Bloom, Harold (1997) [1973]: The Anxiety of Influence. The Theory of Poetry. Oxford New York: Oxford University Press.

Coelno, Jacinto do Prado (1983): Camões e Pessoa, poetas da utopia. Lisboa: Europa-América.

Costa, Dalila L. Pereira da (1971): O esoterismo de Fernando Pessoa. Porto: Lello \& Irmão.

Costa, Dalila L. Pereira da (1993): «A mensagem messiânica». In: Fernando Pessoa, Mensagem. Poemas esotéricos. Edição crítica, ed. J.A. Seabra, Madrid: Coleção Archivos. Fundação eng. A. Almeida, 259-279.

Coutinho, Jorge (1995): O pensamento de Teixeira de Pascoaes. Estudo hermenêtico e crítico. Braga: Publicações da Faculdade de Filosofia da Universidade Católica Portuguesa.

Cusatis, Brunello de (2005): Esoterismo, Mitogenia e Realismo Político em Fernando Pessoa. Uma visão do conjunto. Porto: Edições Caixotim.

Frias, Eduardo (1971): O Nacionalismo Místico de Fernando Pessoa. Braga: Pax. 
Lopes, Teresa Rita (1993): «Mensagem de uma vida». In: Fernando Pessoa, Mensagem. Poemas esotéricos. Edição crítica, ed. J.A. Seabra. Madrid: Coleção Archivos. Fundação eng. A. Almeida, 344-353.

Mendes, Luísa Maria Bernardino de Medeiros de Brito (2004): O Quinto Império de Fernando Pessoa ou a criação literária em língua portuguesa. Tese de doutoramento não publicada, Lisboa.

Moisés, Carlos Felipe (1979): «Fernando Pessoa - sonho e realidade», Persona n. ${ }^{\circ}$ 3, Porto: Centro de Estudos Pessoanos, 61-68.

Pascoaes, Teixeira de (1988): A Saudade e o Saudosismo. Dispersos e opúsculos. Lisboa: Assírio \& Alvim.

PessoA, Fernando (1979a): Sobre Portugal. Introdução ao problema nacional, introdução e organização J. Serrão. Lisboa: Ática.

PessoA, Fernando (1979b): Da República (1910-1935), recolha de textos M.I. Rocheta, M.P. Morão, introdução e organização J. Serrão. Lisboa: Ática.

PessoA, Fernando (1980): Ultimatum e páginas de sociologia política, recolha de textos M.I. Rocheta, M.P. Morão, introdução e organização J. Serrão. Lisboa: Ática.

PessoA, Fernando (1993): Pessoa Inédito, coordenação T. Rita Lopes. Lisboa: Livros Horizonte.

PessoA, Fernando (1996): Páginas íntimas e de auto-interpretação, textos estabelecidos e prefaciados por G. R. Lind e J. do Prado Coelho. Lisboa: Ática.

PINTo, António Costa (1996): «Modernity versus Democracy? The Mystical Nationalism of Fernando Pessoa», separata de The intellectual revolt against liberal democracy 1870-1945. International Conference in Memory of Jacob L. Talmon. Jerusalem, 343-355.

PIRES, António Machado (1982): D. Sebastião e o Encoberto. Lisboa: Fundação Calouste Gulbenkian.

Quadros, António (1989): A ideia de Portugal na literatura portuguesa dos últimos 100 anos. Lisboa: Fundação Lusíada.

Quadros, António (2001): Poesia e filosofia do mito sebastianista. Lisboa: Guimarães Editora.

SADLIER, Darlene J. (1998): Nationalism, Modernism, and the Formation of Pessoa's Aesthetics. In: D.J. SADLIER, An introduction to Fernando Pessoa: Modernism and the Paradox of Authorship. Gainsville: University Press of Florida, 27-47.

Seabra, José Augusto (1980): «Camões, Pascoaes, Pessoa - ou o mito poético da «Nova Renascença», Nova Renascença, Porto, n. ${ }^{\circ}$ 1, 23-31.

Serrão, Joel (1981): Fernando Pessoa, Cidadão do Imaginário. Lisboa: Livros Horizonte.

SiEwIERSKI, Henryk (1982): «Mito e verdade na Mensagem de Fernando Pessoa». Separata do Boletim Cultural da Assembleia Distrital de Lisboa, III Série, Lisboa, n. ${ }^{\circ} 88$, tomo 2.

Siewierski, Henryk (1998) «Orędzie Fernanda Pessoy». In: H. Siewierski, Jak dostałem Brazylię w prezencie. Kraków: Universitas, 30-43.

TAVARES, José Fernando (2002): Fernando Pessoa: da razão histórica à utopia teológica. Introdução a uma teoria da história. Lisboa: Instituto Piaget.

TeIXeIrA, Luís Filipe B. (1993): «A Mensagem ou o "espírito da utopia” como paradigma pessoano». In: Fernando Pessoa, Mensagem. Poemas esotéricos. Edição crítica, ed. J.A. Seabra. Madrid: Coleção Archivos. Fundação eng. A. Almeida, 314-328.

VieIra, António (1992): História do futuro, introdução, actualização do texto e notas por M.L. Carvalhão Buescu. Lisboa: INCM. 